\title{
Production of Biodiesel (B100) from Jatropha Oil Using Sodium Hydroxide as Catalyst
}

\author{
Joshua Folaranmi \\ Department of Mechanical Engineering, Federal University of Technology, Niger State, Minna 920262, Nigeria \\ Correspondence should be addressed to Joshua Folaranmi; folajo2008@yahoo.com
}

Received 17 September 2012; Accepted 24 November 2012

Academic Editor: Alireza Bahadori

Copyright (C) 2013 Joshua Folaranmi. This is an open access article distributed under the Creative Commons Attribution License, which permits unrestricted use, distribution, and reproduction in any medium, provided the original work is properly cited.

\begin{abstract}
This research work is about the production of biodiesel from jatropha oil. Other oils can also be used for the production, but jatropha was chosen because it is not edible therefore, it will not pose a problem to humans in terms of food competition. Before the transesterification process was carried out, some basic tests such as free fatty acid content, iodine value, and moisture content were carried out. This was done so as to ascertain quality yield of the biodiesel after the reaction. The production of the biodiesel was done with standard materials and under standard conditions which made the production a hitch-free one. The jatropha oil was heated to $60^{\circ} \mathrm{C}$, and a solution of sodium methoxide $\left(\right.$ at $60^{\circ} \mathrm{C}$ ) was added to the oil and stirred for 45 minutes using a magnetic stirrer. The mixture was then left to settle for 24 hours. Glycerin, which is the byproduct, was filtered off. The biodiesel was then thoroughly washed to ensure that it was free from excess methanol and soap. The characterization was done at NNPC Kaduna refinery and petrochemicals. The result shows that the product meets the set standard for biodiesel.
\end{abstract}

\section{Introduction}

There is a continuous search for renewable sources of fuels due to the rate of depletion of fossils. The term biofuel is used to define fuels that are obtainable from plants or animals. Being a renewable source, it is gaining attention all over the world today. Biofuel is defined as fuel comprising of monoalkyl esters of long fatty acids derived from vegetable oils or animal fats [1]. These fuels could be either in the form of vegetable oils or animal fats that have been transformed by chemical or natural processes for use in powering various engines. Biofuels are obtained from renewable energy sources such as biological materials from living organisms and can also be obtained from biodegrade waste. Hence, the term biomass is used to describe the sources of biofuels. These are wastes from plants and animals that are capable of being used as fuels in their original form or with little modification. These wastes can also be used in production of fibres and chemicals that are essential to our daily lives. The term biofuel is not the same with fuels from fossils, the major difference between biofuels and fossil fuel is in their carbon content and the amount of emission they give off when burnt [2].
Various types of engines manufactured today are made to run on a wide variety of fuels, such as premium motor spirit (petrol), diesel, or gas as their primary fuel, with all these types of engines, the diesel engine is the one most suitable to run on biofuel. Also, biofuels are very similar to diesel fuel in composition; therefore, there is no need for engine modification to run on biofuels. Diesel engine burns less fuel producing the same amount of work when compared to a petrol engine [3]. Biodiesel is a carbon-neutral source of fuel and is increasingly becoming popular. This is a liquid fuel that is created by chemically processing vegetable oil and altering its properties to make it perform like petroleum diesel. Biodiesel is very similar to petro diesel, but they are not identical. However, the difference is remarkably small when we compare the procedure for making biodiesel and petro diesel [4]. Biodiesel is made through a chemical process called transesterification; this process involves altering the chemical properties of a vegetable oil by using methanol [5]. Transesterification of vegetable oil is a relatively simple process that yields high conversion with glycerin as the only byproduct. In modern times, the need to find and develop alternative energy sources is on the increase; this is largely 
due to a decline in the appeal of traditional energy sources such as fossil fuel which has been around for many years. Fossil fuels have been linked to various environmental and ecological problems which have risen from their method of extraction, production, and eventually their intended point of use [6]. The use of these energy sources over many years has resulted in global temperature levels also known as global warming. This is due to high levels of carbon that are released as byproduct and exhaust gases. This unfortunate situation gave rise to the search for alternative sources of fuels that are more environmentally friendly, the negative effect of petroleum-based fuels. Over the years there has been a steady increase in the amount of pollution produced by these fuels. Their methods of extraction have also led to serious cases of oil spills which tend to destroy the immediate or remote environment where such resources are found [3]. This has also led to many political and socioeconomic problems over the world. Therefore, the search for other source of fuel began as early as 1800 during the early production of combustion engine. During this period, various oils were used to run engines until the mass production of various fuels overtook the older fuels. In Africa, especially Nigeria, there is a huge potential for the development of biofuels as an alternative energy source, this is due to the fact that there is wide variety of plants produced in the country that could be used as biofuel sources [7]. Oils from Jatropha, melon, palm oil, soybean, sugar cane, and used oil can be used to make biodiesel. Jatropha is very important in the production of biodiesel since it is a nonedible plant and will not cause competition on human food. Advances in the use of biodiesel as an alternative fuel are aimed at providing cheap and renewable energy, which is easy to manufacture and more importantly clean and more environmentally friendly [8]. The production of this fuel can be encouraged at the grass root level to aid ordinary Nigerians use biodiesel as fuel alternative. This will fill the gap and more importantly relieve pressure on crude oil as the dominate fuel in the running of equipment [9]. The objective of this study is to produce biodiesel from Jatropha oil, test its properties, and compare its properties with that of petrol diesel.

\section{Materials and Methods}

2.1. Materials. Materials and apparatus used in the production of the biodiesel are as follows: thermometer, retort stand, pipette, measuring cylinder, separating funnel, magnetic stirrer, oven, water bath, hydrometer, conical flask, digital weighing balance, stop watch, hot plate, distilled water, methanol, and jatropha oil.

2.2. Method. Steps in biodiesel production: two steps are used in the production of the biodiesel as shown in Figure 1 below.

(i) Reduction of the fatty acid contained in the Jatropha oil.

(ii) Transesterification.
2.2.1. Reduction of the Fatty Acid. As obtained in the test carried out on the jatropha oil, it was discovered that the free fatty acid (FFA) contents of oil are high (21.6\%). Hence, it became necessary to reduce it.

Procedure. Crude jatropha oil was poured into a conical flask and heated to a temperature of $60^{\circ} \mathrm{C}$. A mixture of concentrated $\mathrm{H}_{2} \mathrm{SO}_{4}(1 \% \mathrm{w} / \mathrm{w})$ with methanol $(30 \% \mathrm{v} / \mathrm{v})$ was heated separately at $\left(50^{\circ} \mathrm{C}\right)$ and then added to the heated oil in the flask. The mixture was stirred for 1 hour and allowed to settle for 2 hours.

2.2.2. Transesterification. The step by step approach used in the production of the biodiesel is given below.

(i) $10.5 \mathrm{~mL}$ of jatropha oil was measured and poured into $250 \mathrm{~mL}$ conical flask and heated to a temperature of $50^{\circ} \mathrm{C}$.

(ii) A quantity of methanol was poured in a round bottom flask and soxhlet apparatus, and the heater was turned on. This was done to purify the methanol.

(iii) The sodium hydroxide pellet was placed in the weighing balance to get exactly $0.25 \mathrm{~g}$.

(iv) A solution of potassium methoxide was prepared in a $250 \mathrm{~mL}$ beaker using $0.25 \mathrm{~g}$ (i.e., catalyst concentration of $0.5 \%$ ) of sodium hydroxide pellet and $63 \mathrm{~mL}$ (i.e., mole ratio of oil to methanol of $1: 6$ ) of methanol. The solution was properly stirred until potassium hydroxide pellet was completely dissolved.

(v) The potassium methoxide solution was placed in the oven to bring its temperature to $60^{\circ} \mathrm{C}$.

(vi) The potassium methoxide solution was then poured into the warm jatropha oil and stirred vigorously for 50 minutes using a magnetic stirrer. The mixture was then allowed to settle for 24 hours in a separating funnel.

(vii) The biodiesel was then poured into a separate beaker, while the lower layer (which comprises of glycerol and soap) was collected from the bottom of the separating funnel.

(viii) Warm water was then used to wash the biodiesel to remove any excess glycerol and soap that remain in the funnel. This was done until the clear water was seen below the biodiesel in the separating funnel.

(ix) The washed sample was dried by placing it on a hot plate and excess water still in the biodiesel was removed.

(x) The quantity of biodiesel collected was measured and recorded.

(xi) The above procedures were repeated by varying the mole ratio of jatropha and methanol, while keeping catalyst concentration, stirring time, and temperature constant. 


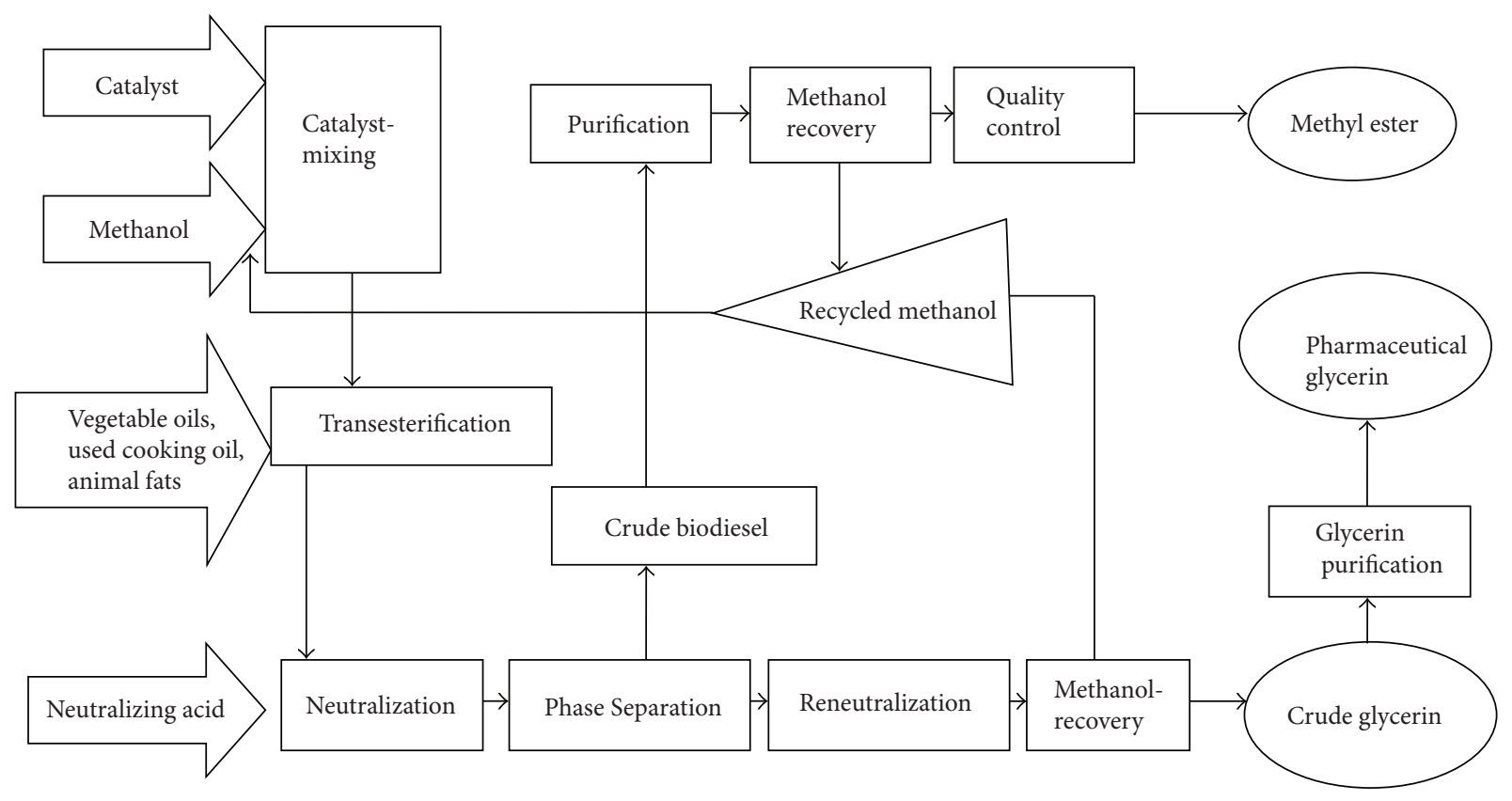

Figure 1: Production of biodiesel.

\section{Characterization of Jatropha Oil}

\subsection{Determination of Viscosity}

Procedure. The oil sample was filtered through a sintered glass (fire mesh screen) to remove dust and other solid materials. The viscometer was charged with the sample by inverting the tube's thinner arm into the liquid sample and suction force was drawn up to the upper timing mark of the viscometer, after which the instrument was turned to its normal vertical position. The viscometer was placed into a holder and inserted to a constant temperature bath set at $30^{\circ} \mathrm{C}$; the sample was left for some minutes until it attained $300^{\circ} \mathrm{C}$. The suction force was then applied to the thinner arm to draw the sample slightly above the upper timing mark. The afflux time by timing the flow of the upper timing mark to the lower timing mark was recorded.

\subsection{Determination of Moisture Content}

Procedure. The oil sample was weighed and the mass taken as $\left(w_{1}\right)$ thus was then dried in the oven and the weight after drying was taken as $\left(w_{2}\right)$. The percentage moisture in the oil was then calculated using the formula below:

$$
\% \text { moisture content }=\frac{w_{1}-w_{2}}{w_{1}} \times 100
$$

where: $w_{1}$ is the weight of oil sample before drying (grams), and $w_{2}$ is the weight of oil sample after drying (grams).

3.3. Determination of Free Fatty Acid. The free fatty acid in the oil was determined by titrating it against Potassium hydroxide $(\mathrm{KOH})$ using phenolphthalein as indicator.
Procedure. $2 \mathrm{~g}$ of oil was dissolved in $50 \mathrm{~mL}$ of the neutral solvent in $250 \mathrm{~mL}$ conical flask, 3 to 4 drops of phenolphthalein indicator was then added and titrated against $0.1 \mathrm{~m}$ $\mathrm{KOH}$. The content was constantly stirred until a pink colour which persisted for fifteen seconds was obtained.

3.4. Determination of Specific Gravity. Density bottle was used to determine the density of the oil. A clean dry bottle of $25 \mathrm{~mL}$ was weighed $\left(w_{0}\right)$ and then filled with the oil; a stopper was inserted and then reweighed to give $\left(w_{1}\right)$. The oil substituted with water after washing and drying and weighed to give $\left(w_{2}\right)$ as

$$
\text { Specific gravity }=\frac{w_{1}-w_{0}}{w_{2}-w_{0}}
$$

\subsection{Determination of Iodine Values}

Procedure. $0.5 \mathrm{~g}$ of the oil was weighed into a $250 \mathrm{~cm}^{3}$ glass stopper bottle. $15 \mathrm{~cm}^{3}$ of chloroform was added to dissolve it, followed by $25 \mathrm{~cm}^{3}$ of wijis iodine solution. The bottle was placed in the dark and allowed to stay for 30 minutes, after which $20 \mathrm{~cm}^{3}$ of $15 \%$ potassium iodine (KI) solution was added; the bottle was stoppered and shaken vigorously. This solution was titrated against a standard $0.1 \mathrm{~m}$ sodium thiosulphate solution. Titration was done with constant shaking until yellow colour of iodine almost disappears. $2 \mathrm{~cm}^{3}$ of $1 \%$ starch indicator was added and titration continued. When the colour disappeared, bottle was covered with a stopper and shaken vigorously so that any iodine in the organic solvent layer will pass into the water layer. Finally, when the titration was completed, the titer values were recorded. Blank determination was carried out on $5 \mathrm{~mL}$ of chloroform and of 


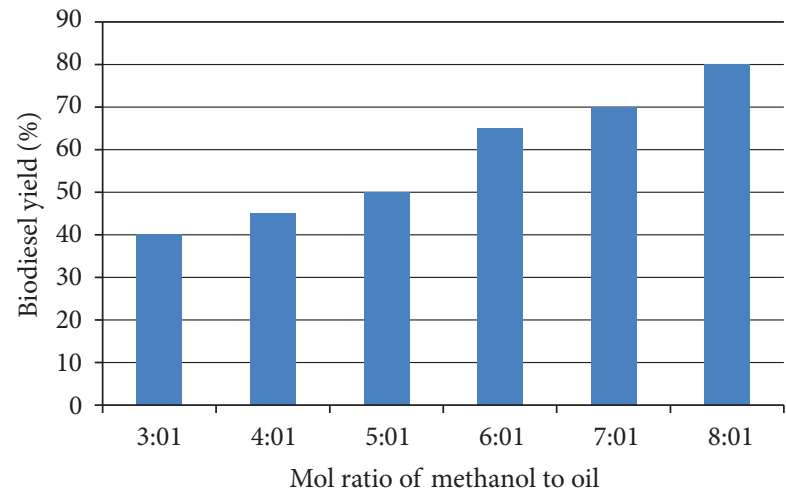

FIGURE 2: Effect of molar ratio of methanol to oil on biodiesel yield.

equal proportion of wijis solution allowing the precipitate to dissolve for same length of time as for the sample analyzed.

3.6. Determination of Saponification Value. A known quantity of oil was refluxed with an excess amount of alcoholic $\mathrm{KOH}$, after saponification, the remaining $\mathrm{KOH}$ was estimated by titrating against a standard acid.

Procedure. The oil sample was filtered to remove any impurities and last traces of moisture. $5 \mathrm{~g}$ of the sample was then weighed into a flask and $5 \mathrm{~mL}$ of alcoholic $\mathrm{KOH}$ was added from burette allowing it to drain for the same duration of time. A reflux condenser was connected to the flasks and allowed to boil gently for one hour. After the flask and condenser get cooled, they were rinsed down the inside of the condenser with a little distilled water and then the condenser was removed. About $1 \mathrm{~mL}$ of indicator was added and titrated against $0.5 \mathrm{~m}$ HCL until the pink colour disappeared.

3.7. Determination of Peroxide Value. The peroxide present was determined by titrating against thiosulphate solution in the presence of KI using starch as indicator.

Procedure. $1 \mathrm{~g}$ of the oil was weighed into a clean dry boiling tube. $1 \mathrm{~g}$ of powder KI and $2 \mathrm{~mL}$ of solvent mix was then added and transferred into boiling water and allowed to boil vigorously for not more than 30 seconds. The content was transferred quickly to a conical flask containing $20 \mathrm{~mL}$ of $5 \% \mathrm{KI}$ solution. The tube was washed twice with $25 \mathrm{~mL}$ of water each time and collected into the conical flask. $0.002 \mathrm{~m}$ $\mathrm{Na}_{2} \mathrm{~S}_{2} \mathrm{O}_{3}$ was titrated with the solution until the yellow colour almost disappeared. Also, $0.5 \mathrm{~mL}$ of starch was added and mixed vigorously and was carefully titrated until blue colour just disappeared. A blank was also set at the same time.

\section{Results}

See Tables 1, 2, 3, 4, 5, and 6, and Figures 2, 3, and 4.

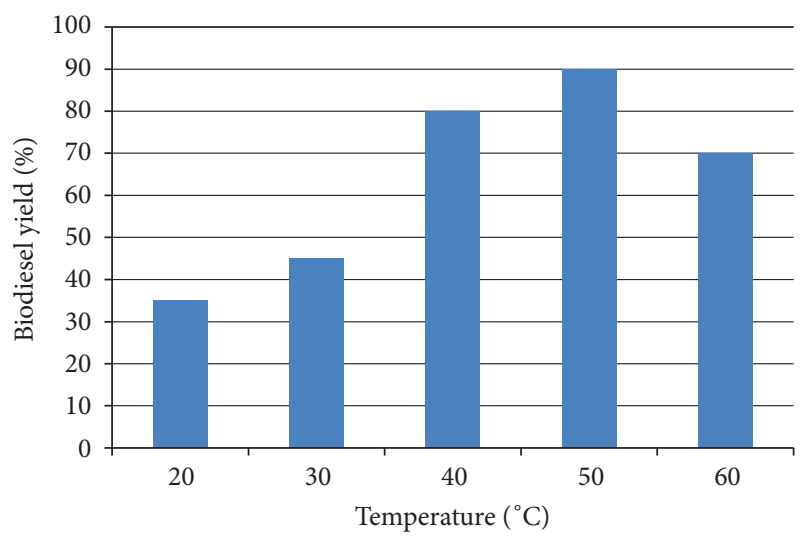

FIGURE 3: Effect of temperature of mixture on biodiesel yield.

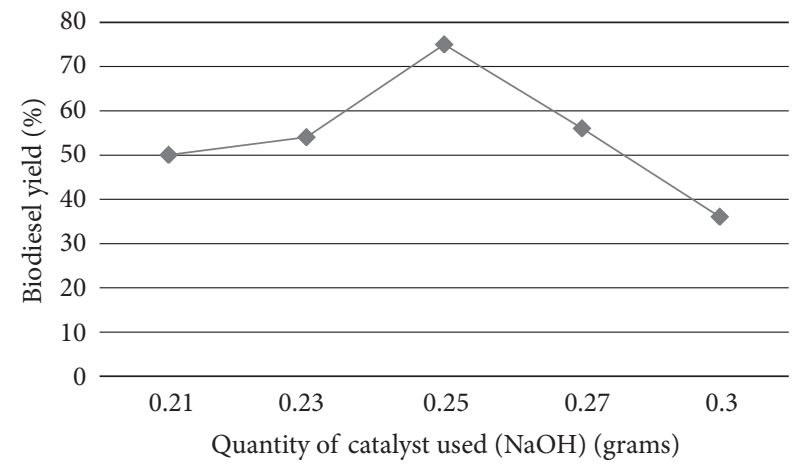

FIgURE 4: Effect of catalyst on biodiesel yield.

\section{Discussion of Results}

The results of this research work will be discoursed under the following groups of solution:

(i) analysis of the Jatropha oil sample,

(ii) production and yield of biodiesel,

(iii) analysis of the result from the characterization of the biodiesel produced.

5.1. Analysis of the Jatropha Oil Sample. From Table 1, the various properties of the jatropha oil used are within range of the standard in Table 2. As observed, the saponification value of the jatropha oil is 190; this is within the range given in Table 2. This property is very important because if it is too high the formation of soap will be more prevalent instead of the desired biodiesel. Another property that is very important is the moisture content. From Table 1, the value is 0.20 . If the moisture content of the oil sample is too high, soap formation will be more and there will be problems with the separation of the by-product (Glycerin). Free fatty acid level and PH are also very important; more glycerin will be formed if the $\mathrm{PH}$ is too high. The two properties are within the range of the standard as seen in the table.

5.2. Production and Yield of Biodiesel. The chemical reaction that yielded the biodiesel was carried out under standard 
TABLE 1: Properties of the jatropha oil used for biodiesel production.

\begin{tabular}{lc}
\hline Property & Value \\
\hline Refractive index & 1.46 \\
Iodine value & 102 \\
Specific gravity & 0.912 \\
PH & 5.62 \\
Free fatty acid & 18.4 \\
Saponification value $(\mathrm{mg} \mathrm{KOH} / \mathrm{g})$ & 190 \\
Moisture content & 0.20 \\
Acid value \% & 38.1 \\
Viscosity (cp) & 50.7 \\
\hline
\end{tabular}

TABLE 2: Standard specification of jatropha oil.

\begin{tabular}{lc}
\hline Property & Value \\
\hline Colour & 4.0 \\
Specific gravity & 0.9186 \\
Carbon residue & 0.64 \\
Cetane value & 51.1 \\
Distillation point & $295^{\circ} \mathrm{C}$ \\
Kinematic viscosity & $50.73 \mathrm{cs}$ \\
Sulphur \% & $0.13 \%$ \\
Calorific value & $9470 \mathrm{kcal} / \mathrm{kg}$ \\
Pour point & $8^{\circ} \mathrm{C}$ \\
Acid value & $1.0-38.2$ \\
Iodine value & $90.8-112.5$ \\
Saponification value & $188-198$ \\
\hline
\end{tabular}

TABLE 3: Standard specifications of petrol diesel.

\begin{tabular}{lc}
\hline Property & Value \\
\hline Specific gravity & $0.82-0.845$ \\
Flash point & $50^{\circ} \mathrm{C}$ \\
Carbon residue & 0.15 or less \\
Cetane value & 50.0 \\
Distillation point & $350^{\circ} \mathrm{C}$ \\
Kinematic viscosity & $2.7 \mathrm{cs}$ \\
Sulphur \% & $1.2 \%$ \\
Calorific value & $10170 \mathrm{kcal} / \mathrm{Kg}$ \\
Pour point & $10^{\circ} \mathrm{C}$ \\
Colour & 4.0 \\
\hline
\end{tabular}

conditions. Samples were kept at the right temperature, and equipment and materials were kept very clean. The required mol of the catalyst $(\mathrm{KOH})$ was used so as to prevent emulsification. The mixture was stirred rigorously so that the reactants will mix very well and produce the highest yield of biodiesel possible under the given condition. The biodiesel produced is free from glycerol and soap because warm water was used to wash the biodiesel. This is necessary so that the properties of the biodiesel produced will be acceptable when compared with the standard. Emulsification is a major drawback that can occur if the reactants are not properly handled, this is a situation whereby soap molecules encase
TABLE 4: Characterization of the biodiesel produced.

\begin{tabular}{lccc}
\hline Property & Unit & Limit (ASTMD6751) & Result \\
\hline Specific gravity & $\mathrm{kg} / \mathrm{L}$ & $0.95 \mathrm{max}$ & 0.90 \\
Kinematic viscosity & $\mathrm{c} . s . t$ & $1.9-6.0$ & 4.93 \\
Cloud point & ${ }^{\circ} \mathrm{F}$ & $40 \mathrm{max}$ & 37 \\
Flash point & ${ }^{\circ} \mathrm{F}$ & $130 \mathrm{~min}$ & 138 \\
Cetane number & - & $40 \mathrm{~min}$ & 52 \\
Water by distillation & $\% \mathrm{vol}$ & $0.5 \mathrm{max}$ & Trace \\
Free glycerin & $\% \mathrm{mass}$ & $0.02 \mathrm{max}$ & 0.05 \\
Total glycerin & $\% \mathrm{mass}$ & $0.24 \mathrm{~min}$ & 0.32 \\
Ash content & $\% \mathrm{wt}$ & $0.1 \mathrm{max}$ & $\mathrm{ND}$ \\
Carbon residue & $\% \mathrm{wt}$ & $15 \mathrm{max}$ & $\mathrm{ND}$ \\
Gross calorific value & $\mathrm{cal} / \mathrm{gm}$ & $10600 \mathrm{~min}$ & $\mathrm{ND}$ \\
\hline ND: not determined. & & &
\end{tabular}

TABLE 5: Effect of molar ratio of methanol to oil on biodiesel yield.

\begin{tabular}{lcc}
\hline S/no & Molar ratio of methanol to oil (mol) & Biodiesel yield (\%) \\
\hline 1 & $3: 1$ & 40 \\
2 & $4: 1$ & 45 \\
3 & $5: 1$ & 50 \\
4 & $6: 1$ & 65 \\
5 & $7: 1$ & 70 \\
6 & $8: 1$ & 80 \\
\hline
\end{tabular}

TABLE 6: Effect of temperature of mixture on biodiesel yield.

\begin{tabular}{lcc}
\hline S/no & Temperature of mixture $\left({ }^{\circ} \mathrm{C}\right)$ & Biodiesel yield (\%) \\
\hline 1 & 20 & 35 \\
2 & 30 & 45 \\
3 & 40 & 80 \\
4 & 50 & 90 \\
5 & 60 & 70 \\
\hline
\end{tabular}

the biodiesel molecules. This can be corrected (if it happens) by heating the mixture and allowing it to settle. Also, hot solution of sodium chlorine can be used to break the encasing molecules. The heat decreases the density of the oil, while the salt increases the density of the water. Two litres of jatropha oil was used and the yield was two litres of biodiesel.

5.3. Analysis of the Result from the Characterization of the Biodiesel Produced. The characterization of the biodiesel produced was carried out at the NNPC refinery in Kaduna, the result is presented in Table 4 . The result is placed with the corresponding limit set for (ASTMD6751) biodiesel standard. The cloud point and pour point of the biodiesel produced are higher than that of the petrol diesel. The pour point is the temperature below which the fuel will not flow. As a result of this higher value, the performance of the biodiesel in cold conditions will be worse than that of petroleum diesel [10]. One of the most important characteristics of any fuel is its flash point; this is defined as the lowest temperature at which it can vaporize to form an ignitable mixture in air. The biodiesel has a higher flash point of $138^{\circ} \mathrm{F}$ as compared 
to that of the petrol diesel (flash point of 50). This makes the biodiesel sample safe for use and storage. Also, fuels with lower flash point tend to ignite at lower temperature making it highly dangerous if it is not stored and used properly. The cetane number is another important property of fuels; this is a measure of the combustion quality of a diesel during compression ignition. The ignition quality, as a result of the cetane number, affects engine performance, cold starting, warm up, and engine combustion roughness. Cetane rating is related to the volatility of the fuel where more volatile fuels have higher ratings. A high cetane fuel also may lead to incomplete combustion and smoke if the fuel ignites too soon by not allowing enough time for the fuel to mix with air for complete combustion. Generally, diesel engines will run with values between 45 and 55 [11], the biodiesel produced has a value of 52 , which is well within range; it is hence suitable to run in diesel engines. Another important value is the viscosity of the fuel; viscosity is a measure of resistance to flow of a liquid due to internal friction of one part of a fluid moving over another. This property is of utmost importance in fuels. The viscosity of a fuel is important because it affects the atomization of the fuel being injected into the engine combustion chamber. A small fuel drop is desired so that complete combustion can occur. A high viscosity fuel will produce a larger drop of fuel in an engine combustion chamber which may not burn as clean as a fuel that produces a smaller drop. Unburned oxidized fuel will build up in the engine around valves, injector tips and on piston sidewalls and rings. The higher the viscosity, the greater the tendency of the fuels to cause problems such as clogging of engine components. However, the viscosity of the biodiesel produced is within the range as given by ASTM standards for biodiesels. The density of a fuel is another important factor for good engine performance; the higher the density, the more difficult it becomes to pump the fuel. The specific gravity of the biodiesel produced is 0.895 ; this is well within the range of the standard.

\section{Conclusion}

In the current investigation, it has confirmed that jatropha oil may be used as resource to obtain biodiesel. The experimental result shows that alkaline-catalyzed transesterification is a promising area of research for the production of biodiesel in large scale. Materials for use in the production of biodiesel are readily available without the need for special equipment or scarce chemicals. Used oil from restaurant can be used. Oil from trees can also be used in the production of biodiesel. On small scale production, the cost of production is low, but if mass production and accuracy is the goal, the cost is high. Glycerin which is the by-product of the chemical reaction can be sold to the pharmaceutical companies, since it is used to produce valuables such as creams and toothpaste. Effects of different parameters such as temperature, time, reactant ratio, and catalyst concentration on the biodiesel yield were analyzed. The best combination of the parameters was found as $8: 1$ molar ratio of methanol to oil, $1.0 \% \mathrm{KOH}$ catalyst, $60^{\circ} \mathrm{C}$ reaction temperature and 60 minutes of reaction time.
This optimum condition yielded $90 \%$ of biodiesel. From the characterization of the biodiesel, the physical properties of biodiesel from jatropha oil with methanol were found to be within the ASTM specified limits. The viscosity of jatropha oil reduces substantially after transesterification and is comparable to diesel. Biodiesel characteristics like density and viscosity are comparable to that of the petrol diesel.

\section{References}

[1] Q. Junfeng, S. Haixlan, and Y. Zhi, Preparation of Biodiesel From Jatropha Circas Oil Produced By Two-Phase Solvent Extraction, Pergamon Press, 2010.

[2] W. Marshall, L. G. Schumacher, and S. A. Howell, "Engine Exhaust Emissions Evaluation of a Cummins L10E When Fueled with a Biodiesel Blend," SAE Paper No. 952363, SAE, Warrendale, Pa, USA, 1995.

[3] Hansen and C. Alan, "Combustion and Emission characteristics of Biodiesel Fuel," CABER Seminar, Department of Agricultural and Biological Engineering, University of Illinois, Urbana, Ill, USA, Pp 6., 2008.

[4] “DOE, Biodiesel Green Diesel Fuel,” DOE/GO-102001-1449, National Renewable Energy Lab, US Department of Energy, February, 2002.

[5] Silveira and D. Foster, "Availability of Biomass Across the Globe," 2008, http://www.forestencyclopedia.net/.

[6] N. E. Leadbeater and L. M. Stencel, "Fast, easy preparation of biodiesel using microwave heating," Energy and Fuels, vol. 20, no. 5, pp. 2281-2283, 2006.

[7] J. C. Thompson, C. L. Peterson, D. L. Reece, and S. M. Beck, "Two-year storage study with methyl and ethyl esters of rapeseed," Transactions of the American Society of Agricultural Engineers, vol. 41, no. 4, pp. 931-939, 1998.

[8] C. L. Peterson, J. C. Thompson, J. S. Taberski, D. L. Reece, and G. Fleischman, "Long-range on-road test with twenty-percent rapeseed biodiesel," Applied Engineering in Agriculture, vol. 15, no. 2, pp. 91-101, 1999.

[9] L. G. Schumacher, S. C. Borgelt, and W. G. Hires, "Fueling a diesel engine with methyl-ester soybean oil," Applied Engineering in Agriculture, vol. 11, no. 1, pp. 37-40, 1995.

[10] C. Peterson and D. Reece, "Emissions characteristics of ethyl and methyl ester of rapeseed oil compared with low sulfur diesel control fuel in a chassis dynamometer test of a pickup truck," Transactions of the American Society of Agricultural Engineers, vol. 39, no. 3, pp. 805-816, 1996.

[11] G. Knothe, G. Jon Van, and K. Jurgen, The Biodiesel Handbook, Champaign, Ill, USA, 2005. 

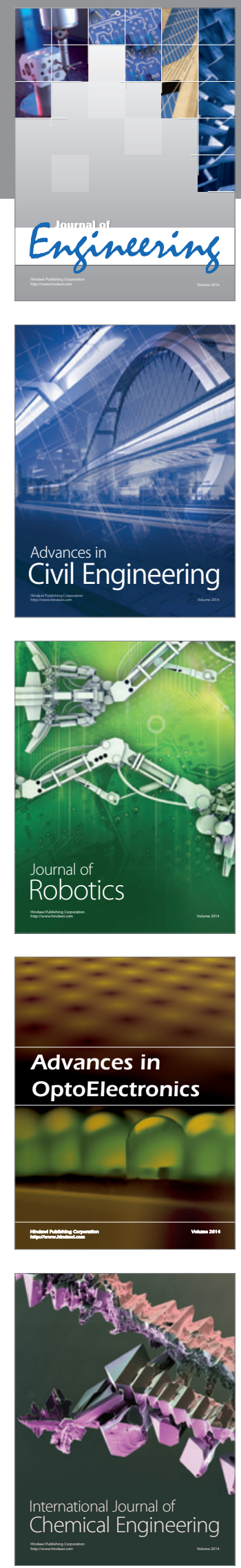

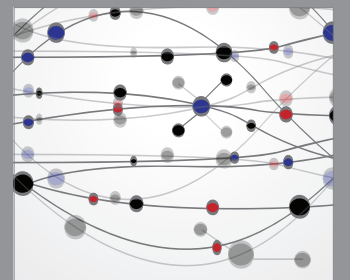

The Scientific World Journal
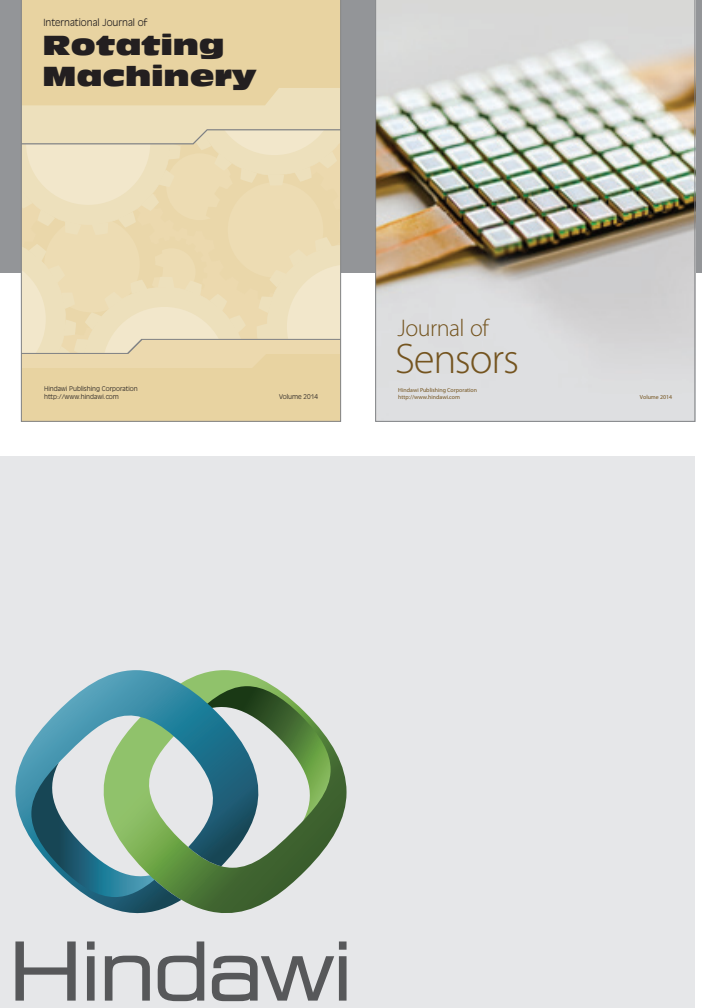

Submit your manuscripts at http://www.hindawi.com
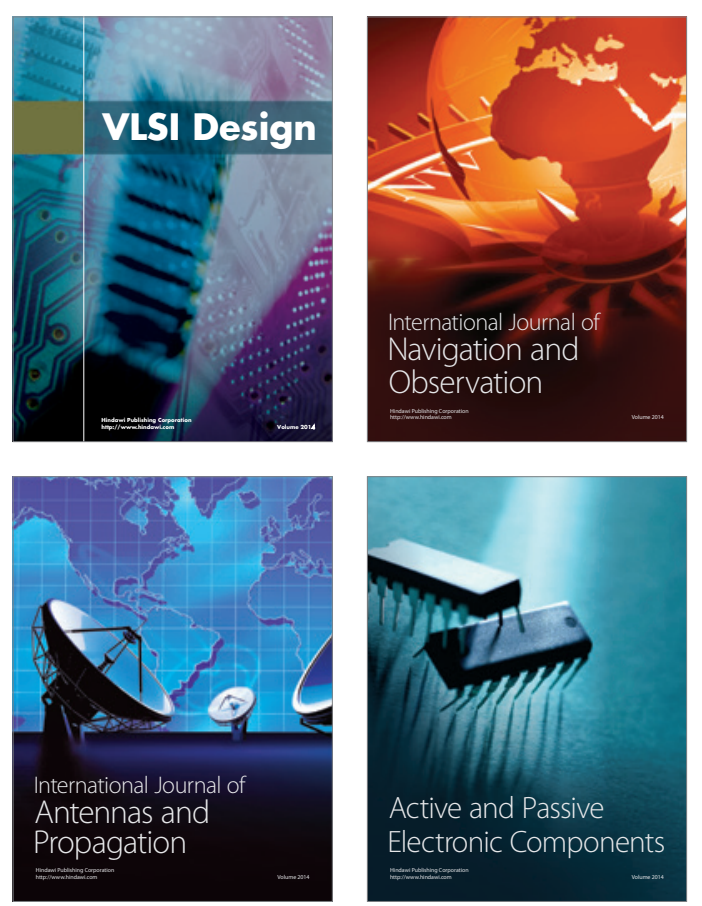
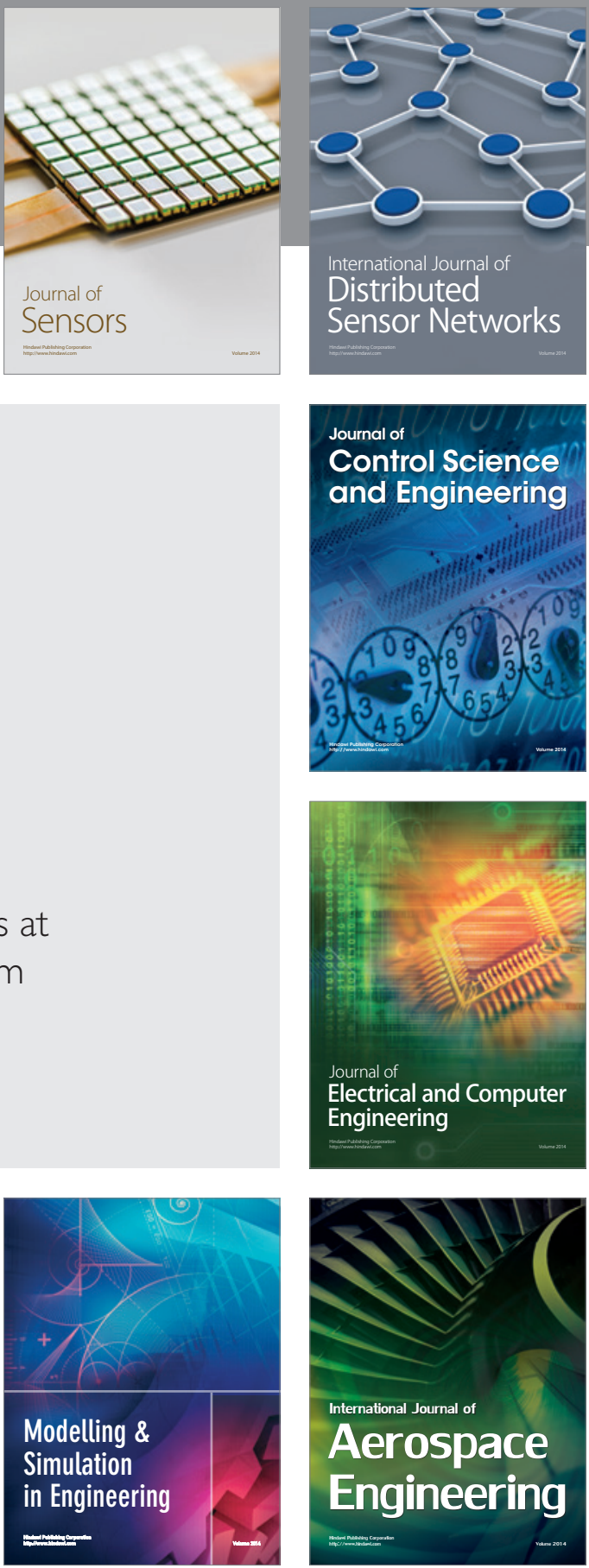

Journal of

Control Science

and Engineering
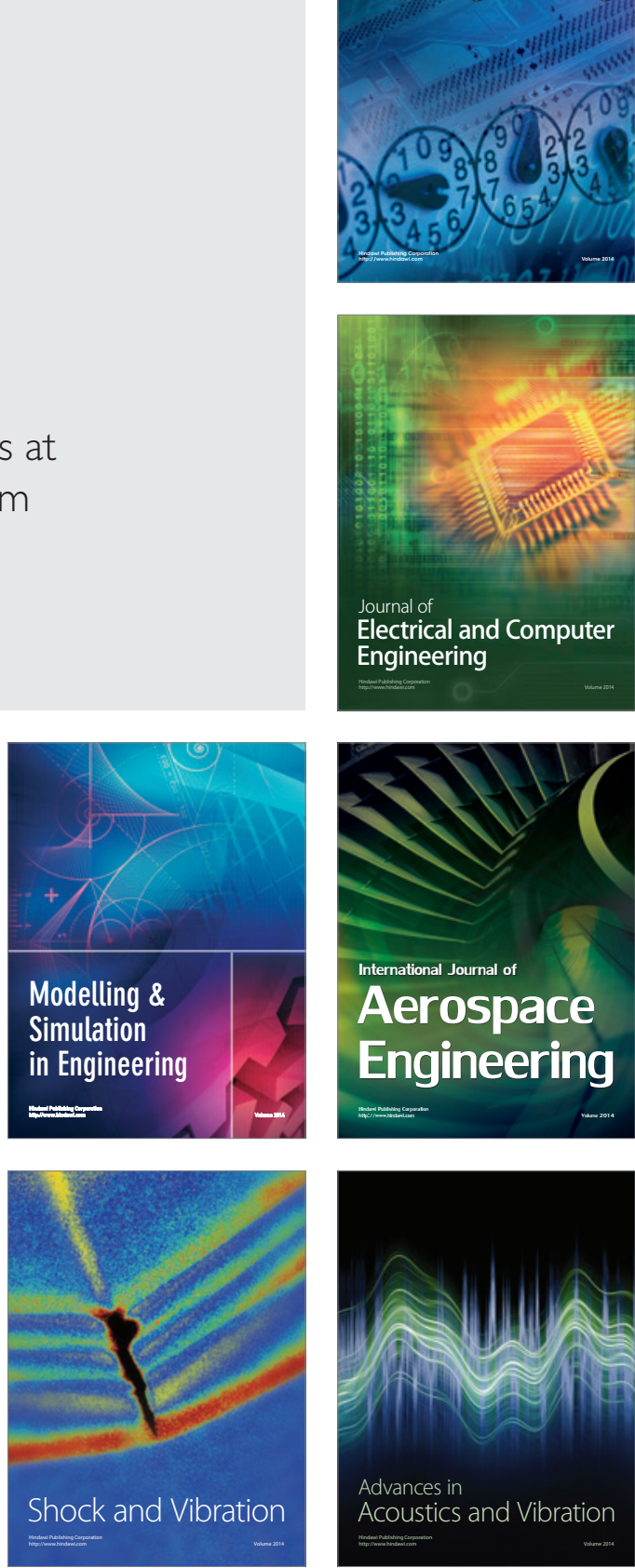